\title{
O modelo de proteção social brasileiro: notas para a compreensão do desenvolvimento da seguridade social
}

Valter Martins ${ }^{1}$

\section{Resumo}

O presente artigo tem como objetivo problematizar o desenvolvimento do modelo de proteção social brasileiro e suas implicações para o acesso aos direitos de cidadania. O estudo trata-se de uma reflexão teórica. Inicialmente, caracteriza a associação do sistema de proteção social quanto à concepção de direito social. Na sequência, aborda a origem da proteção social e seu desenvolvimento até a Constituição da República Federativa do Brasil de 1988, com destaque para a nova concepção das políticas públicas sociais, advindas do desdobramento do conceito de Seguridade Social. Assegurando, assim, a evolução do modelo de proteção social como direito contratual até atingir sua universalização. Nessa direção, espelha um padrão de bem-estar que contempla as demandas de redução das desigualdades, com políticas e ações concretas de afirmação dos direitos sociais, apontando os direitos com forte relação entre Estado e cidadãos. A seguir, exibe as mudanças no cenário político que resistem à implementação dos direitos sociais, na forma inaugurada pela Constituição Federal de 1988, burlando o desenho original da proteção social brasileira, bem como seus desdobramentos para as políticas públicas. Os principais resultados apontam para um modelo de proteção social institucionalizado, porém de frágil atenção à sua demanda, requerendo complementação do mercado. Conclui que, apesar de a Constituição ter significado um avanço singular para a proteção social brasileira, sua efetivação pouco representou para o conjunto da população. Considera, ainda que num período marcado por profundas transformações no mundo do trabalho, principalmente ligadas ao aumento do desemprego estrutural e do subemprego, o modelo de proteção social tem convergido para uma lógica de acesso via mercado, restringindo a cidadania ao poder de compra das pessoas, implicando, assim,

1 Mestre em Serviço Social, doutorando em Serviço Social - PUC/SP. Professor do Departamento de Serviço Social (DSS/UFSC). Atua nas áreas de Serviço Social e Políticas Sociais. 
diretamente na forma e conteúdo das políticas públicas sociais que constituem o sistema de proteção social.

Palavras-chave: Proteção social. Seguridade Social. Políticas públicas. Cidadania.

\section{Introdução}

O termo "direito" tornou-se, na atualidade, uma expressão disseminada e largamente utilizada no vocabulário corrente, vindo a ser empregado para caracterizar uma infinidade de eventos, normalmente ligados àquilo que é justo ou que está em conformidade com a lei. Assim, muitas vezes, ouvem-se reclamos por uma infinidade de direitos que, na maioria das vezes, estão relacionados a bens materiais ou à sua reposição. Todavia, o "conceito de direito conota capacidade de outorga, isto é, capacidades para realizar atividades sem risco de interferência arbitrária ou injusta”.

Sendo assim, os direitos apresentam-se como uma dimensão estrutural, conferindo oportunidades e obrigações sempre outorgadas e implementadas dentro de um ordenamento político-jurídico, ou quando este ratifica acordos com outros ordenamentos político-jurídicos, ou, ainda, quando estabelece acordos com instituições que representem interesses comuns à humanidade.

O direito perpassa por diversas esferas, porém, no presente texto, será abordado o Direito à Assistência Social, entendido como o conjunto de normas com as quais o Estado provê as necessidades gerais dos trabalhadores, ou não, fazendo-os beneficiários do sistema de proteção social.

Para balizar o conteúdo, colocar-se-á o princípio da autonomia como mecanismo qualificador para a construção da cidadania, principalmente ao afirmar que as pessoas devem gozar de direitos iguais, tendo, consequentemente, obriga-

2 HELD, D. Desigualdades de poder, problemas da democracia. In: MILIBAND, D. Reinventando a esquerda. São Paulo: Unesp, 1997. p. 69. 
ções iguais. Desse modo, as pessoas deveriam ser livres na definição das condições de suas próprias vidas, ${ }^{3}$ entendendo, portanto, que, ao nascer, cada indivíduo encontra-se num todo heterogêneo, fazendo com que este acabe por reproduzir as condições de vida do núcleo familiar.

As determinações de ordem material auferem ao homem, ao nascer, a condição de pertencer a uma classe historicamente dominante e/ou a outra classe subordinada aos interesses mais gerais da primeira.

Com o avanço da história e o enraizamento no tecido social do modelo individualista de sociedade, pautado na Declaração dos Direitos de Virgínia de 1776 e na Declaração Francesa de 1789, estabeleceu-se uma perspectiva entre governo e governados. Nessa trajetória, conforme a classificação de Marshall ${ }^{4}$ em Cidadania, Classe Social e Status, os direitos são classificados em três momentos, contidos em períodos históricos distintos. São apresentados, em primeiro lugar, os direitos civis, surgidos no século XVIII; em segundo, os direitos políticos, concebidos no século XIX; e, por último, os direitos sociais como produto do século XX. ${ }^{5}$

Considerando o tema do esboço - sistema de proteção social como direito -, torna-se a classificação supracitada parâmetro alocativo do modelo de proteção inaugurado no campo dos direitos sociais na Constituição da Republica Federativa do Brasil de 1988.

Pode-se situar o sistema de proteção social amplamente ligado aos dois últimos direitos classificados por Marshall e Bobbio. Nesse sentido, aponta Bobbio ${ }^{6}$ que:

3 HELD, D. Desigualdades de poder, problemas da democracia. In: MILIBAND, D. Reinventando a esquerda. São Paulo: Unesp, 1997. p. 69.

4 MARSHALL, T. H. Cidadania, classe social e status. Rio de Janeiro: J. Zahar, 1967.

5 Essa classificação também é incorporada por Norberto Bobbio em BOBBIO, N. A era dos direitos. Rio de Janeiro: Campus, 1992.

6 BOBBIO, N. A era dos direitos. Rio de Janeiro: Campus, 1992. p. 5-6. Introdução, Primeira Parte: sobre os fundamentos dos direitos do homem; presente e futuro dos direitos do homem. 
[...] a liberdade política e as liberdades sociais, do nascimento, crescimento e amadurecimento do movimento dos trabalhadores assalariados, dos camponeses com pouco ou nenhuma terra, dos pobres que exigem dos poderes públicos não só o reconhecimento da liberdade pessoal e das liberdades negativas, mas também a proteção ao trabalho contra o desemprego, os primeiros rudimentos de instrução contra o analfabetismo, depois a assistência para a invalidez e a velhice, todas elas carecimentos que os ricos proprietários podiam satisfazer por si mesmos.

O autor sugere que tais exigências passam a existir somente quando nascem determinados carecimentos, tendo-se aí novas necessidades que surgem em função da mudança das condições sociais e, ainda, quando o desenvolvimento técnico permite satisfazê-los.

A partir do advento das necessidades das classes trabalhadoras, oriundas do conflito do modelo de produção, a reivindicação surge como solo fértil para as primeiras políticas públicas sociais que substanciaram os sistemas de proteção social nascentes. Entretanto, a necessidade de modernização dos países para garantir a industrialização também se fez presente nesse processo, proporcionando as condições objetivas para a implantação de parques industriais, ao passo da regulamentação do trabalho assalariado.

\section{Breve histórico da proteção social}

As políticas públicas sociais brasileiras desenvolveram-se a partir do início do século passado, configurando um tipo de padrão de proteção social só alterado com a Constituição da República Federativa do Brasil de 1988.

O sistema de proteção social brasileiro, até o final da década de 80, combinou um modelo de seguro social na área previdenciária, já a atenção à saúde embasava-se num modelo assistencial para a população sem vínculos trabalhistas formais, ou seja, o acesso à saúde era privilégio de quem estava no mercado de trabalho formal. Enquanto isso, a assistência social parcamente desenvolvia-se com status de caridade aos pobres. 
O desenho acima citado consolidou-se no Governo de Getúlio Vargas, especialmente entre as décadas de 1930 e 1940, como parte do processo mais geral de construção do estado moderno brasileiro, que se preparava para embasar a industrialização, além da intervenção e da centralização após o Golpe de 1930. A título de ilustração, foram criados nessa época os Institutos de Aposentadorias e Pensões (IAP) em substituição às Caixas de Aposentadorias e Pensões (CAP), a Legião Brasileira de Assistência (LBA) e o Ministério do Trabalho e Emprego.

As diferenças entre o modelo de seguro social aplicado à Previdência Social e o modelo assistencial são ilustradas por Fleury, ${ }^{7}$ a seguir:

No modelo assistencial, as ações, de caráter emergencial, estão dirigidas aos grupos de pobres mais vulneráveis, inspiram-se em uma perspectiva caritativa e reeducadora, organizam-se em base à associação entre trabalho voluntário e políticas públicas, estruturam-se de forma pulverizada e descontínua, gerando organizações e programas muitas vezes superpostos.

Assim, a autora diz que, embora esse modelo permita o acesso a certos bens e serviços, não configura uma relação de direito social, pois, na verdade, trata-se de medidas compensatórias que terminam por ser estigmatizantes. Dessa maneira, a tese supõe essa relação como de "[...] cidadania invertida na qual o indivíduo tem que provar que fracassou no mercado para ser objeto da proteção social". ${ }^{8}$

Segue a autora, ao abordar o modelo de seguro social, afirmando que:

[...] a proteção social dos grupos ocupacionais estabelece uma relação de direito contratual, na qual os benefícios são condicionados às contribuições pretéritas e à afiliação dos indivíduos a tais categorias ocupacionais que são autorizadas a operar um seguro. A organização altamente fragmentada dos seguros expressa a concepção dos benefícios como privilégios diferenciados de cada categoria, como resultado de sua capacidade de pressão sobre o governo. Como os direitos sociais estão condicionados à inserção dos indivíduos na estrutura produtiva, Wanderley G. dos Santos

7 FLEURY, S. Novas bases para a retomada da seguridade social. Revista Praia Vermelha: Estudos de Política e Teoria Social, Rio de Janeiro, 9 jul. 2003. p. 2.

8 BOBBIO, N. A era dos direitos. Rio de Janeiro: Campus, 1992. 
(1979) denominou a relação como de cidadania regulada pela condição de trabalho ${ }^{9}$.

Constata-se, ainda, que, no período da democracia populista (1946-1963), a expansão do sistema de seguro social viria a fazer parte do jogo político de intercâmbio de benefícios por legitimação dos governantes, beneficiando de forma diferenciada os grupos de trabalhadores com maior poder de barganha e também extratos da população que mantinham relações de apadrinhamento. Nesse contexto, houve a massificação de privilégios, implicando no aprofundamento da crise financeira e da administração do sistema previdenciário.

Já no regime burocrático-autoritário, iniciado em 1964, os mecanismos de proteção social passam a obedecer a quatro parâmetros: no primeiro, dá-se a centralização e a concentração do poder nas mãos da tecnocracia, com a retirada dos trabalhadores do jogo político e da administração das políticas públicas sociais; no segundo, ocorre o aumento de cobertura, incorporando, marginalmente, grupos anteriormente excluídos, por exemplo, as empregadas domésticas, os trabalhadores rurais e os autônomos; como terceiro parâmetro, dá-se a criação de fundos e contribuições sociais como mecanismo de autofinanciamento dos programas sociais - como o Fundo de Garantia por Tempo de Serviço (FGTS) -, que financiou a política habitacional através do Banco Nacional da Habitação (BNH); e, por último, a “[...] privatização dos serviços sociais, principalmente os ligados à educação universitária, [à do ensino médio] à atenção hospitalar." ${ }^{10}$

Na década de 70, no Brasil, como também em vários outros países da América Latina, foram registrados o surgimento e o ressurgimento de um expressivo número de movimentos sociais. Eclodiram do tecido social brasileiro movimentos de classe como os sindicais, os urbanos e rurais, os movimentos das classes trabalhadoras e, entre as camadas populares, a luta pautou-se por bens de consumo coletivo, nos setores de infraestrutura urbana. ${ }^{11}$ Além disso, também, surgem os

9 FLEURY, S. Novas bases para a retomada da seguridade social. Revista Praia Vermelha: Estudos de Política e Teoria Social, Rio de Janeiro, 9 jul. 2003. p. 2.

${ }^{10}$ BOBBIO, N. A era dos direitos. Rio de Janeiro: Campus, 1992. p. 2.

${ }^{11} \mathrm{Na}$ década de 70, as camadas populares reinvidicavam, sobretudo, por serviços de saúde, educação, transporte, habitação, etc. 
chamados novos "movimentos sociais". ${ }^{12}$ Esses movimentos somam-se às inquietações presentes no cenário político da época, até então confinadas nas universidades e nos partidos políticos clandestinos, que juntos consubstanciaram a luta pela redemocratização.

Na segunda metade da década de 70, há ainda o fortalecimento das capacidades técnicas dos partidos políticos e do parlamento, que passam a tomar a problemática social como parte de seu terreiro e de seus projetos de construção de uma sociedade democrática.

No discurso, o resgate da dívida social é o tema central da agenda da democracia, convergindo para ele movimentos de naturezas diversas. Tal processo intensifica-se na década de 80 , por meio do surgimento de um rico tecido social emergente a partir da aglutinação do novo sindicalismo e dos movimentos reivindicatórios urbanos, como apontou Gohn anteriormente, e, também, da construção de uma frente partidária da oposição e da organização de movimentos setoriais, capazes de formular projetos de reorganização institucional, como o Movimento Sanitário. ${ }^{13}$

Todo esse movimento da sociedade decorre da abertura política, com o início dos trabalhos da Assembleia Nacional Constituinte, tendo este sujeito coletivo redesenhado, junto com a participação da sociedade, uma nova ordem institucional democrática que supunha um reordenamento das políticas públicas sociais que respondesse às demandas da sociedade por maior inclusão social e equidade. Como resultado, a Constituição da Republica Federativa do Brasil de 1988 projetou seus pressupostos para o sistema de políticas públicas sociais que se espelhava num padrão de bem-estar que desse conta da redução das desigualdades, adquirindo políticas e ações concretas com "[...] conotações de afirmação dos direitos sociais como parte da cidadania.".

\footnotetext{
${ }^{12}$ Esses movimentos não apresentavam vinculações com classes exclusivas, mais eram compostos por um conjunto heterogêneo de interesses, como a título de ilustração: os feministas, os homossexuais, os ecológicos, os negros etc. GOHN, M. da G. Movimentos sociais e luta pela moradia. São Paulo: Loyola, 1991.

${ }_{13}$ BOBBIO, N. A era dos direitos. Rio de Janeiro: Campus, 1992.

${ }^{14}$ GOHN, M. da G. Movimentos sociais e luta pela moradia. São Paulo: Loyola, 1991.
} 


\section{Constituição da República Federativa do Brasil de 1988: a seguridade social em foco}

O discurso sobre direito social, em conjunto com a promulgação da Constituição Federal de 1988, baliza um novo estágio no marco legal à edificação dos direitos sociais no Brasil, "[...] afirmando que a ordem social tem como base o primado do trabalho, e como objetivo o bem-estar e a justiça social", ${ }^{15}$ desdobrando-se no núcleo duro de atenção, ao articular na Seguridade Social um conjunto de ações, destinado a assegurar os direitos relativos à saúde, à previdência e à assistência social, rompendo, dessa forma, com as matrizes que orientavam o modelo de proteção social brasileiro inaugurado no irromper do século XX.

É fato que os fundamentos constitucionais 1988 se deram no processo de abertura política e de democratização e com a necessidade de se ampliar o padrão de cidadania. Assim, a partir dos movimentos da sociedade e da articulação de setores da economia, processou-se a luta pela redemocratização do aparelho político e estatal, a fim de substanciar melhores condições para a população, auferindo patamares de cidadania por meio de medidas que promovessem o bem-estar e a justiça social para uma nação subalternizada secularmente.

O desenho inaugurado na estrutura do Estado, com a nova Constituição, possibilitou garantias ao conjunto da população, principalmente mediante o preceito de universalismo da Seguridade Social. Dentro dessa concepção, a Assistência Social rompe com a ideia secularizada de caridade e ganha status de direito, fomentando um conjunto de ações e indicações para o amparo e o provimento das condições necessárias para se resguardar a vida, nas suas dimensões concretas. O conjunto de indivíduos que historicamente encontravam-se fora do sistema de proteção social ganhou, com a Constituição da República Federativa do Brasil de 1988, uma perspectiva, ao serem incluídos num sistema de proteção social, sem que, para isso, estivessem inseridos no mercado de trabalho formal. Portanto, a tese fundamental da Seguridade Social, tendo aí a saúde, a previdência e a assistência social, a partir da Constituição Federal de 1988, ressignifica o padrão de direito social.

${ }^{15}$ BRASIL. Constituição da República Federativa do Brasil: promulgada em 5 de outubro de 1988. 27. ed. São Paulo: Saraiva, 2001. (Coleção Saraiva de Legislação). 
A partir de então, são reconhecidos, no âmbito da legislação brasileira, direitos fundamentais ao conjunto da população, convergidos num padrão de cidadania.

$\mathrm{Na}$ base teórica, Norberto Bobbio ${ }^{16}$ aponta que os direitos apresentam-se numa profunda relação entre Estado e cidadãos, donde a passagem do homem abstrato para o homem concreto, ou seja, do campo das ideias para o campo material das necessidades, se dá por meio de um processo gradativo de diferenciação ou especificação dos carecimentos e dos interesses, dos quais se solicita o reconhecimento e a proteção.

Contudo, o movimento brasileiro de reconhecimento pelo Estado das necessidades materiais e da ampliação da proteção social ao conjunto dos cidadãos não se deu espontaneamente. Não obstante, por mais fundamentais que possam parecer, como salienta Bobbio, ${ }^{17}$ num escrito sobre os fundamentos dos direitos do homem, são tidos como "direitos históricos", isto é, nascidos em certas circunstâncias, caracterizadas por lutas em defesa de novas liberdades contra velhos poderes, e de modo gradual.

Destarte, inaugurou-se na década de 80 um novo período no qual o modelo da Seguridade Social brasileiro passa a estruturar a organização e o formato da proteção social nacional, em busca da universalização e da cidadania. No modelo de Seguridade Social, buscou-se romper com as noções de cobertura restrita a setores inseridos no mercado formal e afrouxar os vínculos entre contribuições e benefícios, gerando mecanismos mais solidários e redistributivos. Os benefícios começam a ser concedidos a partir das necessidades, com fundamentos nos princípios da justiça social, o que obriga a estender universalmente a cobertura e integrar as estruturas governamentais.

Observa-se, ainda, na Constituição da República Federativa do Brasil de 1988, que os direitos sociais, ou seus fundamentos e princípios gerais, foram ex-

\footnotetext{
${ }^{16}$ BOBBIO, N. A era dos direitos. Rio de Janeiro: Campus, 1992.

${ }^{17}$ GOHN, M. da G. Movimentos sociais e luta pela moradia. São Paulo: Loyola, 1991. p. 5.
} 
pressos no Capítulo da Ordem Social, em especial nos Artigos 203 e 204 - Da Assistência Social -, passando a existir de modo gradual, ao passo que a Assistência Social se legitimará como política pública e direito concreto ao conjunto da população com a Lei no 8.742/93, que organiza a Assistência Social, em conjunto com a Lei $n^{\circ} 8.909 / 94$, ao dispor sobre o caráter emergencial e as normas de vinculação das entidades prestadoras de serviços. Além dessas, a Ordem de Serviços no 562/97, do Instituto Nacional de Seguro Social (INSS), ao publicar manual de procedimentos para a operacionalização dos benefícios da assistência a idosos e a pessoas com deficiência; a Portaria no 33/97, que aprovou a sistemática operacional para o financiamento das ações de assistência social, que compõem o Sistema de Proteção Social no campo das Políticas Públicas Sociais; a Portaria n 4.385/98 do Ministério de Estado da Previdência Social, que regulamenta serviços, programas e projetos de assistência social; ainda, as Normas Operacionais Básicas da Assistência Social, que concebem a operacionalização da política nacional de assistência social.

No cenário político dos anos de 1980 e de 1990, buscou-se afirmar esse conjunto de diretos sociais baseados na nova ordem social que emergia: a democracia, tendo aí o solo para o reconhecimento dos direitos civis e sociais, que, para Bobbio, ${ }^{18}$ “[... $]$ sem direitos reconhecidos e protegidos, não há democracia; sem democracia não existem as condições mínimas para a solução pacífica de conflitos”. A ideia transmitida pelo autor assenta-se num princípio social liberal, ao conceder direitos ao conjunto da população e esperar que esta se regule por meio de suas instituições.

Diante do ordenamento jurídico, os benefícios passam a ser concedidos a partir das necessidades, com fundamentos nos princípios da justiça social, o que obriga a estender universalmente a cobertura e integrar as estruturas governamentais em seus três níveis - federal, estadual e municipal.

O aparato legal, firmado na Constituição da República Federativa do Brasil de 1988, avançou em relação às formulações anteriores, quando garantiu um

\footnotetext{
${ }^{18}$ BRASIL. Constituição da República Federativa do Brasil: promulgada em 5 de outubro de 1988. 27. ed. São Paulo: Saraiva, 2001. (Coleção Saraiva de Legislação).
} 
conjunto de direitos sociais positivados, inovando ao consagrar o modelo de Seguridade Social ${ }^{19}$ como "[...] um conjunto integrado de ações de iniciativa dos Poderes Públicos e da sociedade, destinadas a assegurar os direitos relativos à saúde, à previdência e à assistência social". ${ }^{20} \mathrm{~A}$ inclusão da previdência, da saúde e da assistência, como partes da seguridade social, introduz a noção de direitos sociais universais como parte da condição de cidadania, sendo que antes eram restritos à população beneficiária da previdência.

O novo padrão constitucional da política pública social caracteriza-se, segundo Sônia Fleury, ${ }^{21}$ pela universalidade na cobertura, reconhecimento dos direitos sociais, afirmação do dever do Estado, subordinação das práticas privadas à regulação em função da relevância pública das ações e serviços nessas áreas, perspectiva publicista de cogestão governo/sociedade e arranjo organizacional descentralizado, que previa a participação da sociedade nas esferas de decisões acerca das políticas que compõem a Seguridade Social.

O direito avançou consideravelmente ao expressar, nesse novo modelo, os princípios organizadores da Seguridade Social: uniformidade e equivalência dos benefícios e serviços às populações urbanas e rurais; seletividade e distributividade na prestação dos benefícios e serviços; irredutibilidade do valor dos benefícios e serviços; equidade na forma de participação do custeio; diversidade da base de financiamento; e gestão quadripartite, democrática e descentralizada, com participação dos trabalhadores, dos empregadores, dos aposentados e do governo em órgãos colegiados. Ademais, introduziu a noção de uma renda de sobrevivência, de

\footnotetext{
${ }^{19} \mathrm{O}$ modelo de seguridade social foi originalmente proposto por Beveridge, definindo-o, em 1942, como "[...] a manutenção dos ingressos necessários à sobrevivência". Sua proposta previa um benefício único universal para aposentadorias, pensões e desemprego, correspondente a um mínimo vital, a ser assegurado pelo sistema público, seja porque o beneficiário cumpriu as condições de tempo de contribuição, seja em casos de necessidade, quando o beneficiário receberia um benefício assistencial depois de comprovada a ausência de recursos. Além disto, previa a "[...] provisão de cuidados médicos, que abarquem a totalidade das necessidades, a todos os cidadãos, mediante um serviço nacional de saúde”. Em FLEURY, S. Estados sem cidadãos. Rio de Janeiro: Fiocruz, 1997. p. 20.

${ }^{20}$ Título VIII, Capítulo II, Seção I, art. 194 de GOHN, M. da G. Movimentos sociais e luta pela moradia. São Paulo: Loyola, 1991.

${ }^{21}$ BOBBIO, N. A era dos direitos. Rio de Janeiro: Campus, 1992.
} 
caráter não contributivo, ao assegurar um benefício financeiro de prestação continuad ${ }^{22}$ para idosos e deficientes incapazes de trabalhar.

A proposta de seguridade articulou três sistemas previamente existentes, regidos por lógicas diversas: a saúde, por meio da necessidade, a previdência, pela condição de trabalho e a assistência, por meio da incapacidade. O entendimento de que a Previdência é um sistema contributivo (art. 201), e que requer uma base de cálculo atuarial para garantir sua sustentabilidade, não a separa do modelo solidário e distributivo da Seguridade Social, pois, no artigo 203, estabelece a assistência social como política integrada à seguridade social, independentemente de contribuição ao regime indicado no artigo 201, e para quem dela necessitar. ${ }^{23}$

Outra questão que preocupa os regimes de arrecadação de sistemas de seguridade social é o fato de que, no Brasil, o modelo pautou-se num conjunto de fontes financiadoras, a partir de 1988, não necessariamente feitas sobre o salário do trabalhador. Nesse sentido, observa-se também que os princípios orientadores da seguridade social não se aplicam igualmente a todos os setores, sendo a universalidade da cobertura o eixo do novo sistema de saúde; e a uniformidade e a equivalência dos benefícios e sua irredutibilidade: ${ }^{24}$ a seletividade e a distributividade, os princípios orientadores da política de assistência social. Verifica-se, assim, uma maior adaptabilidade de princípios às áreas.

O padrão constitucional da proteção social inovou, mesmo em relação ao modelo original, na organização dos setores componentes da Seguridade Social, subordinando-os a dois princípios básicos, à participação da sociedade e à descentralização

\footnotetext{
${ }^{22}$ Legislação atualizada através da Lei 10.741, de $1^{\circ}$ de outubro de 2003, altera a idade de 67 anos para 65 anos de idade mínima para a concessão do Beneficio de Prestação Continuada (BPC). BRASIL. Lei $n^{\circ} 11.737$, de 14 de julho de 2008. Altera o art. 13 da Lei no 10.741, de $1^{\circ}$ de outubro de 2003 - Estatuto do Idoso, para atribuir aos Defensores Públicos o poder de referendar transações relativas a alimentos. Brasília, 2005. Disponível em: <http:// www.planalto.gov.br/ccivil_03/_Ato2007-2010/2008/Lei/L11737.htm>. Acesso em: 09 mar. 2011.

${ }^{23}$ Artigo 201, GOHN, M. da G. Movimentos sociais e luta pela moradia. São Paulo: Loyola, 1991.

${ }^{24}$ A equivalência dos benefícios e sua irredutibilidade compuseram a base da reforma da previdência social.
} 
político-administrativa. Isto é, o novo formato das políticas públicas sociais deveria aprofundar o duplo movimento de democratização, qual seja, desde o nível central em direção ao nível local, e desde o Estado em direção à sociedade. A ênfase na participação da sociedade é um aspecto muito salientado no texto constitucional, refletindo uma resposta às reivindicações dos movimentos sociais em toda a década de 80.

O modelo constitucional ficou caracterizado pelo desenho dos sistemas de políticas sociais de saúde e de assistência de forma descentralizada e participativa. No caso da Previdência, esse modelo não se aplicava completamente, dada a resistência à descentralização, embora houvesse sido criado, inclusive, um conselho onde os beneficiários e contribuintes teriam assento, em resposta à grande mobilização dos aposentados e dos sindicatos.

\section{Contra reforma do sistema de proteção social}

O sistema de proteção social brasileiro, recém inaugurado com a Constituição da República Federativa do Brasil de 1988, sofre, já nos seus primeiros anos, profundos ataques contra a concepção há pouco estabelecida. A correlação de forças que favorecera a promulgação desse modelo constitucional havia mudado, e a promulgação das leis orgânicas só foi possível graças à rearticulação das forças reformistas, diante de um governo com forte orientação liberal.

A partir de meados da década de 90, quando o país vivia o pico de uma forte crise fiscal, inflacionária e política, que despontou no impeachment do então presidente Fernando Collor, observou-se a inflexão na forma de encaminhamento das discussões em torno da Previdência brasileira. A nova agenda incorporou uma intensa discussão pública em relação à sustentabilidade financeira do sistema em virtude das significativas mudanças no mundo do trabalho, além do crescimento dos questionamentos em relação à generosidade do sistema, à manutenção de privilégios para alguns setores e suas distorções gerenciais. ${ }^{25}$

${ }^{25}$ BRASIL. Constituição da República Federativa do Brasil: promulgada em 5 de outubro de 1988. 27. ed. São Paulo: Saraiva, 2001. (Coleção Saraiva de Legislação). 
Nesse momento, em função da crise econômica instaurada, exigia-se uma série de reformas, algumas profundas. Como análise da crise, apresentava-se o alto endividamento público, decorrente da incompetência estrutural do Estado de gerar poupança interna necessária ao desenvolvimento sustentável do país. Com isso, uma política reformista impregnou o Estado, principalmente ao conduzir à privatização do patrimônio público, além da reforma administrativa, introduzindo práticas gerenciais oriundas dos negócios privados, e a retirada do Estado da provisão de serviços. Esse conjunto de diretrizes foi fortemente indicado pelas agências internacionais como a solução capaz de devolver ao país os níveis de crescimento social e econômico alcançados no passado. Nesse arcabouço do discurso reformista, direcionado pela política neoliberal e com orientação ortodoxa na economia, desenvolveram-se os debates acerca da necessidade de reorganização do modelo de seguridade para o país.

A regulamentação do novo desenho constitucional relativo à Seguridade Social foi bastante conflituosa. As leis orgânicas da área de Seguridade Social foram promulgadas após um processo intenso de conflitos e barganhas e em um contexto político em que o Executivo era declaradamente contrário ao seu conteúdo reformista original. Assim, as leis orgânicas da saúde, da previdência e da assistência tiveram que ser negociadas nesse novo momento conjuntural do país, tendo sua “[...] maior ou menor correspondência com os preceitos constitucionais como fruto da capacidade política de resistência às tendências de privatização, recentralização, capitalização e focalização que ameaçaram a implantação da Seguridade Social."26

De acordo com Sônia Fleury, ${ }^{27}$ a maior fragilidade se fez perceber na área de Assistência Social, ${ }^{28}$ dada a baixa capacidade de reivindicação dos usuários des-

\footnotetext{
${ }^{26}$ BOBBIO, N. A era dos direitos. Rio de Janeiro: Campus, 1992. p. 9.

${ }^{27}$ Legislação atualizada através da Lei 10.741, de $1^{\circ}$ de outubro de 2003, altera a idade de 67 anos para 65 anos de idade mínima para a concessão do Beneficio de Prestação Continuada (BPC). BRASIL. Lei no 11.737, de 14 de julho de 2008. Altera o art. 13 da Lei no 10.741, de $1^{\circ}$ de outubro de 2003- Estatuto do Idoso, para atribuir aos Defensores Públicos o poder de referendar transações relativas a alimentos. Brasília, 2005. Disponível em: <http:// www.planalto.gov.br/ccivil_03/_Ato2007-2010/2008/Lei/L11737.htm>. Acesso em: 09 mar. 2011.

${ }^{28}$ Os critérios para obtenção do benefício de prestação continuada (BPC/LOAS, no valor de um salário mínimo) foram definidos de forma tão restritiva que o benefício se tornou excessivamente focalizado, atendendo exclusivamente populações de alto risco social.
} 
ses benefícios, apesar do forte movimento dos profissionais da área, resultando na aprovação da lei orgânica - LOAS - apenas em 1993.

A agenda reformista da década de 90 foi marcada pelo discurso ortodoxo fiscal, que converteu a previdência social no mais grave problema nacional, cuja reforma foi exigida como pré-requisito para o ajuste fiscal e a estabilização da economia. Percebeu-se, assim, que as propostas estavam profundamente formuladas com ênfase no receituário das agências internacionais.

A reforma buscou, sobretudo, reestruturar a previdência social, contanto que liberasse o Estado dos encargos com aposentadorias e pensões e, ao mesmo tempo, fortalecesse o crescente mercado de seguros, apresentando-se como requisito para a solução da crise fiscal.

Entre os campos da reforma, na saúde, predominou um modelo de concessão de serviços básicos para a população empobrecida incapaz de contratar um seguro saúde no mercado, ao passo que, na assistência, o primado universalista reverteu-se num processo de extrema focalização por meio de programas de transferência de recursos. Dessa forma, percebe-se a contrarreforma como produto altamente elaborado do discurso neoliberal para o desmonte dos direitos de proteção social inaugurados na Constituição da República Federativa do Brasil de 1988, especialmente no que tange às responsabilidades do Estado, na prestação e garantia dos direitos universais, com a descentralização e o controle social das políticas públicas.

A pretensiosa reforma se consolida com o Governo de Fernando Henrique Cardoso, em que a Seguridade Social passa por reformas constitucionais, tornando-se a Constituição Federal de 1988 uma "colcha de emendas", desfigurando o modelo de proteção social brasileiro. Nesse período, também as políticas públicas sociais são submetidas à lógica das políticas econômicas.

O profundo descaso com a política pública social entre os anos de 19952001, no Governo FHC, ${ }^{29}$ provocou, em 2001, uma situação orientada para rever-

\footnotetext{
${ }^{29}$ O primeiro mandato de FHC data de 1995-1998 e o segundo, de 1999-2002.
} 
ter a conjuntura disseminada com os rumos do Sistema de Proteção Social, com a proposição da criação de uma 'rede de proteção social", cujo carro chefe são os programas de transferência de renda às famílias pobres, considerando os modelos já desenvolvidos pelo país.

Nesse período, constata-se um aprofundamento da situação de pobreza em grande escala no país, percebendo-se, ainda, o incremento das ocupações terceirizadas e a flexibilização das relações e direitos do trabalhador garantidos na Constituição Federal de 1988.

Com a tentativa de inserir o Brasil na economia internacional, processaram-se reformas na economia, no Estado e, principalmente, no Sistema de Proteção Social no período FHC. Encontrou-se, dessa forma, o Estado brasileiro numa profunda submissão aos interesses dos sujeitos globais, com pouca atenção à integração da economia interna e ao rebaixamento de suas responsabilidades sociais, transferindo uma significativa parcela para a sociedade dos problemas suscitados com as expressões da questão social.

Esse processo encontra-se num patamar de retrocesso do Sistema de Proteção Social, resultando numa política voltada à focalização.

Estando o Sistema de Proteção Social Brasileiro voltado para uma lógica meritocrática e focalizada, embora os ganhos com a Constituição Federal de 1988, principalmente com a LOAS, o que se constata é um profundo rearranjo de atenção ao padrão de proteção social.

Com a eleição de Luís Inácio Lula da Silva, temos indicações de prioridade no enfrentamento da fome e da pobreza no Brasil. Desse modo, apontam as diretrizes ligadas às políticas públicas sociais ao modelo de proteção social ornado no governo anterior. Todavia, o caminho dá-se com mecanismos que perpassam novamente a articulação das políticas públicas sociais, agora com o propósito de enfretamento da fome, perante as políticas econômicas. 
Também, nesse governo, deu-se a unificação de vários programas de redistribuição de renda, sendo estes o meio pelo qual se inaugurou um novo modelo de proteção social para o país, rompendo, assim, com o princípio da universalização impresso na Constituição Federal de 1988, em que as políticas públicas sociais, em especial os Programas de Redistribuição de Renda, passaram a atender grupos restritos e a inserir cada vez mais critérios focalizantes.

Apesar de os programas destacarem a expectativa de romper o círculo da pobreza transgeracional, por meio de uma medida compensatória, percebe-se que eles buscam introduzir as famílias em situação de extrema pobreza em uma rede de segurança social. Tendo em vista elevar os padrões de vida à dignidade, tais programas têm, principalmente, como perspectiva, melhorar o padrão econômico das gerações futuras, com a elevação de sua escolaridade e com o fortalecimento da família. Contudo, o que calha, no fundo, é o recorte da pobreza e o oferecimento de serviços e auxílios concretos, com objetivos de inserir o novo modelo de proteção social para a sociedade brasileira.

\section{Considerações finais}

Os sistemas de proteção social surgem para contingenciar demandas geradas do novo processo originado das formações sociais contemporâneas, pautado, sobretudo, no modo de produção capitalista e, em certa medida, também, para fazer frente à necessidade de apresentar alternativas às classes trabalhadoras diante de uma possibilidade real de outro modelo de sociedade.

Com as grandes transformações ocorridas no romper do século XX, temos diversas formações de modelos de proteção que foram fortemente substanciadas após a Segunda Guerra Mundial, principalmente com o Welfere State, que inaugurou um conjunto de serviços e benefícios sociais de alcance universal promovidos pelo Estado com a finalidade de garantir certa "harmonia" entre o avanço das forças de mercado e uma relativa estabilidade social, suprindo a sociedade de 
benefícios sociais que significam segurança aos indivíduos para manterem um mínimo de base material e níveis de padrão de vida, podendo, assim, enfrentar os efeitos destrutivos de uma estrutura de produção capitalista desenvolvida e excludente.

A extensão tomada pelo Estado, ao atender a provisão das demandas sociais, geradas pelo conflito capital versus trabalho, proporciona um novo estágio e configuração do modelo de acumulação, pautado no desenvolvimento das forças produtivas do capitalismo.

Perante o desenvolvimento das necessidades dos trabalhadores e a garantia de reprodução da força de trabalho, os sistemas de proteção social avançam ao longo dos anos, apresentando-se, na maioria das vezes, como respostas automáticas e mecânicas às necessidades e carências. Mas, muito mais do que isso, representam também formas históricas de consenso político, de sucessivas e intermináveis pactuações, considerando as diferenças existentes no interior da sociedade e sua luta por garantias para a manutenção da vida em suas dimensões concretas e sociais.

Alguns autores que se distanciam do liberalismo, aproximando-se de propostas social-democráticas, e que Gerschman ${ }^{30}$ chama de escola liberal-democrática, acham “[...] que o mercado, liberado de si mesmo, tende a se destruir, e, portanto o Estado deve intervir para contrarrestar os efeitos nocivos do mercado e promover a Seguridade Social às camadas desprotegidas, eliminando as grandes desigualdades sociais”. Esse viés, entendido na concepção keynesiana, busca dar conta dos diversos grupos de interesses que integram o interior do Estado, definindo seus rumos.

Tal fenômeno foi a base de condições para a emergência e o desenvolvimento dos Sistemas de Proteção Social.

\footnotetext{
${ }^{30}$ GERSCHMAN, S. Sobre a formulação de políticas sociais. In: TEIXEIRA, Sônia F. Reforma sanitária: em busca de uma teoria. 2. ed. São Paulo: Cortez; Rio de Janeiro: Associação Brasileira de Pós-Graduação em Saúde Coletiva, 1995. p. 120.
} 
Dessa forma, percebe-se que, quanto menos o mercado "distribui", maior será a mobilização de forças redistributivas pós-mercado para moderar as intensas desigualdades geradas da relação capital versus trabalho.

Percebe-se ainda que, no tecido social brasileiro, os sistemas de proteção social evoluíram de acordo com os interesses da classe abastada, concedendo direitos na forma de benefício para garantirem a ordem e a lógica de produção/ acumulação.

Nesse arco, o Sistema de Proteção Social, a partir dos anos de 1980, os países em desenvolvimento, inclusive o Brasil, foram marcados pelos traços da reforma das políticas públicas sociais, sob a orientação de organismos internacionais como o Banco Mundial e o Banco Interamericano de Desenvolvimento, expresso pela descentralização, privatização e focalização dos programas sociais.

A relação entre Estado e trabalhadores na contemporaneidade denota profunda alteração, se comparada ao pacto de direitos constituído no pós-guerra dos anos 1950, donde a desconstrução do pacto da cidadania, antes amarrado à garantia da Seguridade Social dos direitos trabalhistas, torna-se obsoleta diante dos novos paradigmas apontados pelas agências financeiras internacionais.

A figura do Estado centralizador, fundamental na construção de uma sociedade igualitária para todos, assume nos anos 1990, no Brasil, um processo minimalista de socialização das riquezas produzidas, ao incorporar as concepções do Banco Mundial e do Banco Interamericano de Desenvolvimento e ao direcionar esforços para o “[...] combate da pobreza através de programas e da análise e/ou avaliação dos efeitos [destes] (eficiência, eficácia, efetividade e impacto)”. ${ }^{31}$

No contexto das transformações do Estado regulador para o modelo neoliberal, a questão social exibe novas expressões, considerando-se as novas formas

${ }^{31}$ FREITAS, R. de C. M. Política de combate à pobreza e as agências multilaterais: um estudo comparativo entre o Brasil e México. 2004. Tese (Doutorado em Sociologia Política)-Programa de Pós-Graduação em Sociologia Política, Universidade Federal de Santa Catarina, Florianópolis, 2004. 
de exclusão social e econômica, cujo eixo é representado pelas profundas transformações no mundo do trabalho, principalmente ligadas ao aumento do desemprego estrutural, associado à precariedade do trabalho e às mutações no perfil do trabalhador requerido pelo mercado capitalista globalizado e competitivo.

Tendo em vista as grandes transformações ocorridas nos últimos anos, o Sistema de Proteção Social Brasileiro volta-se para uma lógica meritocrática e focalizada. Embora os ganhos democratizantes e sociais com a Constituição da República Federativa do Brasil de 1988, principalmente com a Lei Orgânica da Assistência Social, o que se constata é um profundo rearranjo de atenção ao que poderíamos chamar de mínimos sociais.

Nesse panorama, edifica-se um novo marco para o Sistema de Proteção Social Brasileiro, tendo-se o redirecionamento ao atendimento focalizado a grupos de risco, como propõem as políticas de redistribuição de renda orientadas pelos organismos internacionais.

\section{The brazilian model for social security: notes for the comprehension of the social security development}

\section{Abstract}

This article aims to discuss the development of the Brazilian model of social protection and its implications for access to citizenship rights. The study is a theoretical reflection Initially, characterizes the association of the social protection system on the concept of social law. Further, it addresses the origin of social protection and its development up to the 1988 Federative Republic of Brazil Constitution, especially the new conception of public social policies arising from the deployment of the concept of social security. Thus, ensuring the evolution of social protection is characterized as a contractual right to achieve its universalization In this direction reflects a pattern of wellness that focuses on the demands for reducing inequality, with policies and concrete actions of affirmation of social rights as part of citizenship rights by pointing to a strong relationship between state and citizen 
Later, displays the changes in the political scenario that resist the implementation of social rights in the form inaugurated by the 1988 Federal Constitution, mocking the original design of the Brazilian social protection, as well as its consequences for public policies. The main results point to an institutionalized social protection model, however fragile attention to its demand, requiring complementation of the market. We conclude, although the Constitution has meant a unique breakthrough to the Brazilian social protection, its materiality just posed to the whole population It considers, though, in a period marked by profound changes in the world of work, mainly linked to an increase in structural unemployment and underemployment, the social protection model has converged to a logic of access through the market, restricting citizenship to the purchasing power of people, thus implying directly in the form and content of public social policies that constitute the social protection system.

Keywords: Social protection. Social security. Public policies. Citizenship

\section{Referências}

BEDIN, G. A. Os direitos do homem e o neoliberalismo. 3 ed. Ijuí: Unijuí, 2002.

BOBBIO, N. A era dos direitos. Rio de Janeiro: Campus, 1992.

BRASIL. Constituição da República Federativa do Brasil: promulgada em 5 de outubro de 1988. 27. ed. São Paulo: Saraiva, 2001. (Coleção Saraiva de Legislação).

BRASIL. Lei $n^{\circ} 11.737$, de 14 de julho de 2008. Altera o art. 13 da Lei no 10.741, de $1^{\circ}$ de outubro de 2003 - Estatuto do Idoso, para atribuir aos Defensores Públicos o poder de referendar transações relativas a alimentos. Brasília, 2005. Disponível em: <http://www.planalto.gov.br/ccivil_03/_Ato2007-2010/2008/Lei/L11737.htm>. Acesso em: 09 mar. 2011.

CONSELHO REGIONAL DE SERVÇO SOCIAL 12를 Região. Coletânea de Leis. 2. ed. Santa Catarina: CRESS, 2001.

FLEURY, S. Estados sem cidadãos. Rio de Janeiro: Fiocruz, 1997. 
FLEURY, S. Novas bases para a retomada da seguridade social. Revista Praia Vermelha: Estudos de Política e Teoria Social, Rio de Janeiro, 9 jul. 2003.

FREITAS, R. de C. M. Política de combate à pobreza e as agências multilaterais: um estudo comparativo entre o Brasil e México. 2004. Tese (Doutorado em Sociologia Política)-Programa de Pós-Graduação em Sociologia Política, Universidade Federal de Santa Catarina, Florianópolis, 2004.

GERSCHMAN, S. Sobre a formulação de políticas sociais. In: TEIXEIRA, Sônia F. Reforma sanitária: em busca de uma teoria. 2. ed. São Paulo: Cortez; Rio de Janeiro: Associação Brasileira de Pós-Graduação em Saúde Coletiva, 1995.

GOHN, M. da G. Movimentos sociais e luta pela moradia. São Paulo: Loyola, 1991.

HELD, D. Desigualdades de poder, problemas da democracia. In: MILIBAND, D. Reinventando a esquerda. São Paulo: Unesp, 1997.

MARSHALL, T. H. Cidadania, classe social e status. Rio de Janeiro: J. Zahar, 1967. 